\title{
MULTIPLE DRUG RESISTANCE PATTERNS IN VARIOUS PHYLOGENETIC GROUPS OF UROPATHOGENIC E.COLI ISOLATED FROM FAISALABAD REGION OF PAKISTAN
}

\section{Saira Bashir, Yasra Sarwar, Aamir Ali, Mashkoor Mohsin, Muhammad Azeem Saeed, Ayesha Tariq, Abdul Haque*}

Health Biotechnology Division, National Institute for Biotechnology and Genetic Engineering (NIBGE), P. O. Box, 577, Jhang Road, Faisalabad, Pakistan.

\begin{abstract}
The objective of this work was the phylogenetic characterization of local clinical isolates of uropathogenic E. coli with respect to drug resistance. A total of 59 uropathogenic E. coli responsible for community acquired urinary tract infections were included in this study. A triplex PCR was employed to segregate each isolate into four different phylogenetic groups (A, B1, B2 and D). Drug resistance was evaluated by disc diffusion method. The drugs used were ampicillin, aztreonam, cefixime, cefoperazone, ceftriaxone, cephradine among $\beta$-lactam group; amikacin, gentamicin, and streptomycin among aminoglycosides; nalidixic acid and ciprofloxacin from quinolones; trimethoprim-sulfomethoxazole, and tetracycline. Among 59 uropathogenic E. coli isolates majority belonged to phylogenetic group B2 (50\%) where as $19 \%$ each belonged to groups A and B1, and 12\% to group D. All the isolates were multiple drug resistant (MDR). Most effective drugs against Group A, B1, and B2 were gentamicin, amikacin and cefixime; ceftriaxone and quinolones; and ceftriaxone and amikacin, respectively. Group D isolates were found to be highly resistant to all drugs. Our results have shown emergence of MDR isolates among uropathogenic E. coli with dominance of phylogenetic group B2. However, it was found that group D isolates were though less frequent, more drug resistant as compared with group B2. Groups A and B1 were relatively uncommon. Amikacin, ceftriaxone and gentamicin were the most effective drugs in general.
\end{abstract}

Key words: uropathogenic E. coli, phylogenetic analysis, drug resistance

\section{INTRODUCTION}

Community acquired urinary tract infections (UTI) are highly prevalent in developing countries and are usually difficult to eradicate because the pathogenic bacteria have acquired resistance to most of the drugs. UTI has been shown to be an independent risk factor for both bladder cancer and renal cell carcinoma (18). Women are more likely to experience UTI than men. UTIs affect a large proportion of the world population and are responsible for significant morbidity and high medical costs $(1,5)$.

Uropathogenic E. coli (UPEC) cause $90 \%$ of urinary tract 
infections (10). The frequent use of antibiotics is considered the most important factor which promotes multiple drug resistance (MDR) in UPEC in both veterinary and human medicine (14).

Different pathotypes of UPEC can be identified by phylogenetic analysis. Phylogenetic studies have revealed that the UPEC are not of very diverse origins and fall into four main groups $\mathrm{A}, \mathrm{B} 1, \mathrm{~B} 2$, and $\mathrm{D}(8,21)$. In the past, phylogenetic groups have been determined by ribotyping, PFGE, RAPD and multilocus enzyme electrophoresis techniques which are very complex and time-consuming. In 2000, Clermont et al. (2) described phylogenetic analysis simply by targeting three genetic markers (chuA, yjaA genes and DNA fragment TSPE4.C2). This method has been found satisfactory and endorsed by other workers (6).

Picard et al. (19) found that UPEC which correspond to phylogenetic group B2 were more susceptible to antibiotics than those falling in A, B1 and D. Moreno et al. (15) investigated that among human UPEC isolates, resistance to quinolones, fluoroquinolones and trimethoprim/ sulfamethoxazole showed shifting from phylogenetic group B2 towards groups A, B1 and/or D.

Due to indiscriminate use of drugs in developing countries, the pathogenic bacteria are much more dynamic, versatile and 'battle-hardened' as compared with developed countries. Therefore, it is predictable that they show variance from established traits. Thus the purpose of this study was to explore local UPEC with respect to phylogenicity and drug resistance. This is the first such report from Pakistan.

\section{MATERIALS AND METHODS}

\section{Collection of samples}

For this study clinically diagnosed patients for UTI were selected from different clinical laboratories of Faisalabad, Pakistan. The criteria included urge to urinate frequently, sharp pain or burning sensation in urethra when urine was released and pyuria. Midstream urine samples were collected in sterile bottles. These samples were stored and transferred to our laboratory at $4^{\circ} \mathrm{C}$ within one week. Only the samples with significant bacteriuria (more than $10^{5} \mathrm{cfu}$ per $\mathrm{ml}$ ) were included.

\section{Isolation and confirmation of UPEC}

The samples were directly inoculated on MacConkey agar plates. After overnight incubation at $37^{\circ} \mathrm{C}$, lactose-fermenting colonies were inoculated on triple sugar iron (TSI) slants for biochemical identification. Confirmation was done by PCR as described below. Fifty-nine UPEC isolates responsible for community acquired UTIs were included in this study.

DNA was extracted by the conventional phenolchloroform method, followed by RNase treatment for the removal of contaminating RNA (20). The quantitative estimation of the isolated DNA was done spectrophotometrically (Lambda 5UV/Vis, Perkin Elmer, USA; Bio projects Gmbh, Germany) at 260nm. PCR for confirmation was performed by targeting conserved region of uid $A$ gene (encoding $\beta$-glucuronidase) of $E$. coli genome by using primers EC-F (5'ATCACCGTGGTGACGCATGTC GC3') and EC-R (5'CACCACGATGCCATGTTCATCTGC3') with an amplification product of 486 bp (7). Each $100 \mu \mathrm{L}$ reaction mixture contained 1x PCR buffer $(50 \mathrm{mM} \mathrm{KCl}, 10 \mathrm{mM}$ Tris $\mathrm{HCl}$; pH 8.3); 2.5 mM $\mathrm{MgCl}_{2}$; dNTP's (dATP, dCTP, dGTP, dTTP) $0.2 \mathrm{mM}$ each; 50 pmol of each primer; $5 \mathrm{U}$ of recombinant Taq polymerase (Fermentas) and 20ng of DNA template. The thermal cycler (MasterCycler; Eppendorf, Hamburg, Germany) conditions were: denaturation for $5 \mathrm{~min}$ at $94^{\circ} \mathrm{C} ; 30$ cycles of amplification at $94^{\circ} \mathrm{C}$ for $1 \mathrm{~min}, 50^{\circ} \mathrm{C}$ for 1 min and $72^{\circ} \mathrm{C}$ for $1 \mathrm{~min}$; and finally extension at $72^{\circ} \mathrm{C}$ for 7 min. The PCR products were visualized by electrophoresis on $2 \%(\mathrm{w} / \mathrm{v})$ agarose gel and photographed by using Eagle Eye (Strategene, USA).

\section{Phylogenetic classification}

The UPEC were assigned to one of the four phylogenetic groups (A, B1, B2 and D) by targeting two marker genes chuA 
(5'GACGAACCAACGGTCAGGAT3'，5'TGCCGCCAGTAC CAAAGACA3') and yjaA (5'TGAAGTGTCAGGAGACG CTG3', 5'ATGGAGAATGCGTTCCTCAAC3'), and a DNA fragment TSPE4.C2 (5'GAGTAATGTCGGGGCATTCA3', 5'CGCGCCAACAAAGTATTACG3') giving amplification products of 279, 211 and 152 bp respectively (2). Briefly, each $100 \mu \mathrm{L}$ reaction mixture was constituted by $1 \mathrm{X}$ PCR buffer (50 $\mathrm{mM} \mathrm{KCl}, 10 \mathrm{mM}$ Tris $\mathrm{HCl} ; \mathrm{pH}$ 8.3); $2.5 \mathrm{mM} \mathrm{MgCl}_{2 \text {; }}$ dNTP's (dATP, dCTP, dGTP, dTTP) $0.2 \mathrm{mM}$ each; 158 pmol of each primer; $5 \mathrm{U}$ of recombinant Taq polymerase (Fermentas); and 20ng of DNA template. The thermal cycler conditions were: denaturation for $5 \mathrm{~min}$ at $94^{\circ} \mathrm{C}$ followed by 30 cycles each of $30 \mathrm{sec}$ at $94^{\circ} \mathrm{C}, 30 \mathrm{sec}$ at $55^{\circ} \mathrm{C}$ and $30 \mathrm{sec}$ at $72^{\circ} \mathrm{C}$, and a final extension step of 7 minutes at $72^{\circ} \mathrm{C}$. The PCR products were visualized by electrophoresis on $2 \%(\mathrm{w} / \mathrm{v})$ agarose gel and photographed by using Eagle Eye (Strategene, USA).

\section{Drug sensitivity by disc diffusion method}

Thirteen drugs encompassing all major groups and their respective generations were used in this study. Drug sensitivity was determined using standard disc diffusion method according to the recommendations of Clinical and Laboratory Standards Institute (15). The discs used were ampicillin (10 $\mu \mathrm{g})$, aztreonam $(30 \mu \mathrm{g})$, cefixime $(5 \mu \mathrm{g})$, cefoperazone $(75 \mu \mathrm{g})$, ceftriaxone $(30 \mu \mathrm{g})$, cephradine $(30 \mu \mathrm{g})$ in $\beta$-lactam group; amikacin $(30 \mu \mathrm{g})$, gentamicin $(120 \mu \mathrm{g})$, and streptomycin $(10$ $\mu \mathrm{g})$ among aminoglycosides; and nalidixic acid $(30 \mu \mathrm{g})$ and ciprofloxacin $(5 \mu \mathrm{g})$ from quinolones. Other drugs were trimethoprim-sulfomethoxazole $(25 \mu \mathrm{g})$ and tetracycline

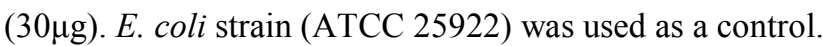

\section{RESULTS}

\section{Phylogenetic classification}

A total of 59 isolates were identified by conventional biochemical identification on TSI slants and confirmed by targeting uidA gene. Out of 59 UPEC isolates, 30 isolates
$(50 \%)$ were classified as phylogenetic group B2 showing two types of gene patterns; 28 isolates were chuA, yjaA and TSPE4.C2 positive where as 2 isolates showed presence of chuA and yjaA genes but TSPE4.C2 was not detected. Seven (12\%) isolates belonged to group $\mathrm{D}$ (chuA positive, yjaA negative and TSPE4.C2 positive) and 11 (19\%) to group A (chuA negative, yjaA positive and TSPE4.C2 negative). Eleven (19\%) isolates fell in the B1 group showing two different patterns of genes; nine isolates had pattern chuA negative, yjaA negative and TSPE4.C2 positive, and two had the pattern chuA negative, yjaA positive and TSPE4.C2 positive (Figure 1).

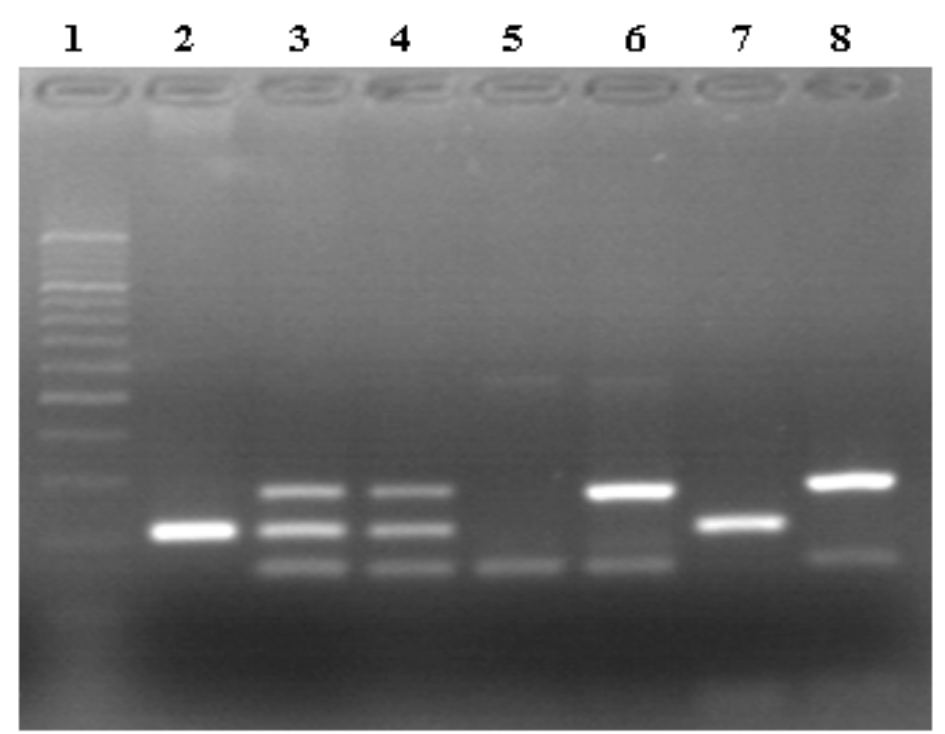

Figure 1. Phylogenetic analysis of uropathogenic E. coli isolates

Lane 1: GeneRuler SM0323 (Fermentas) showing bands of 3000, 2000, 1500, 1200, 1000, 900, 800, 700, 600, 500, 400, 300, 200 and $100 \mathrm{bps}$; Lanes 2 \& 7: Phylogenetic group A isolates showing amplification product of yjaA (211bp); Lanes 3 \& 4: Phylogenetic group B2 isolates showing amplification products of chuA, yjaA and Tspe4.C2 (279 bp, $211 \mathrm{bp}$ and 152 bp); Lane 5: Phylogenetic group B1 isolate showing amplification product of Tspe4.C2 (152bp); Lanes 6 \& 8: Phylogenetic group D isolates showing amplification product of chuA and Tspe4.C2 (279bp and $152 \mathrm{bp}$ ). 


\section{Drug sensitivity by disc diffusion method}

These isolates were highly resistant to cephradine and ampicillin. However, resistance to some other $\beta$-lactam drugs such as aztreonam, and cephalosporins, ceftriaxone, cefoperazone and cefixime was to a lesser degree. Among aminoglycosides, although resistance to streptomycin was very high, gentamicin and amikacin were relatively more effective.
Trimethoprim-sulfamethoxazole and tetracycline were largely ineffective. Nalidixic acid was relatively ineffective but as expected fluoroquinolone, ciprofloxacin showed better results. A total of 43 patterns were observed among E. coli isolates and none of the isolates was resistant to less than 4 drugs, so all isolates were considered as multiple drug resistant (MDR) (Table 1).

Table 1. Prevalence of multiple drug resistance among various phylogenetic groups of uropathogenic $E$. coli isolates

\begin{tabular}{|c|c|c|c|c|c|c|}
\hline \multirow{3}{*}{$\begin{array}{l}\text { Groups } \\
\text { B-Lactams }\end{array}$} & \multirow[t]{2}{*}{ Drugs } & \multirow[t]{2}{*}{$\begin{array}{c}\text { Drug resistance } \\
(\%)\end{array}$} & \multicolumn{4}{|c|}{$\begin{array}{l}\text { Phylogenetic grouping } \\
\qquad(\mathrm{n}=59)\end{array}$} \\
\hline & & & $\begin{array}{l}\mathrm{B} 2 \\
30 \\
(50 \%)\end{array}$ & $\begin{array}{l}\mathrm{D} \\
7 \\
(12 \%)\end{array}$ & $\begin{array}{l}\mathrm{A} \\
11 \\
(19 \%)\end{array}$ & $\begin{array}{l}B 1 \\
11 \\
(19 \%)\end{array}$ \\
\hline & $\begin{array}{l}\text { Cefixime } \\
\text { Cefoperazone } \\
\text { Ceftriaxone } \\
\text { Cephradine }\end{array}$ & $\begin{array}{l}40(68) \\
39(66) \\
30(51) \\
59(100)\end{array}$ & $\begin{array}{l}22(73) \\
21(77) \\
15(50) \\
30(100)\end{array}$ & $\begin{array}{l}7(100) \\
6(86) \\
5(71) \\
7(100)\end{array}$ & $\begin{array}{l}6(55) \\
7(64) \\
7(64) \\
11(100)\end{array}$ & $\begin{array}{l}9(82) \\
5(45) \\
4(36) \\
11(100)\end{array}$ \\
\hline Aminoglycoside: & $\begin{array}{l}\text { Ampicillin } \\
\text { Aztreonam } \\
\text { Amikacin } \\
\text { Gentamicin } \\
\text { Streptomycin }\end{array}$ & $\begin{array}{l}57(97) \\
39(66) \\
33(56) \\
37(63) \\
57(97)\end{array}$ & $\begin{array}{l}30(100) \\
19(60) \\
16(53) \\
14(47) \\
30(100)\end{array}$ & $\begin{array}{l}7(100) \\
6(80) \\
6(86) \\
6(80) \\
7(100)\end{array}$ & $\begin{array}{l}10(91) \\
6(55) \\
5(45) \\
6(55) \\
10(91)\end{array}$ & $\begin{array}{l}10(91) \\
7(64) \\
5(45) \\
6(55) \\
10(91)\end{array}$ \\
\hline Sulfonamide & $\begin{array}{l}\text { Trimethoprim } \\
\text { Sulfamethoxazole }\end{array}$ & $50(85)$ & $26(87)$ & $7(100)$ & 10(91) & $7(64)$ \\
\hline $\begin{array}{l}\text { Quinolones } \\
\text { Fluoroquinolone: } \\
\text { Tetracycline }\end{array}$ & $\begin{array}{l}\text { Nalidixic acid } \\
\text { Ciprofloxacin } \\
\text { Tetracycline }\end{array}$ & $\begin{array}{l}44(75) \\
41(69) \\
53(90)\end{array}$ & $\begin{array}{l}23(77) \\
21(70) \\
27(90)\end{array}$ & $\begin{array}{l}7(100) \\
7(100) \\
7(100)\end{array}$ & $\begin{array}{l}10(91) \\
9(82) \\
9(82)\end{array}$ & $\begin{array}{l}4(36) \\
4(36) \\
10(91)\end{array}$ \\
\hline
\end{tabular}

\section{Drug sensitivity of different phylogenetic groups}

The results of drug resistance according to phylogenetic groups are shown in Table 1. Dominating group among our local UPEC isolates was B2 (50\%). The isolates belonging to this group were highly resistant to all drugs except gentamicin (47\%), ceftriaxone (50\%) and amikacin (53\%). Group D (12\%) isolates were totally resistant to all drugs except cefoperazone, aztreonam, amikacin, gentamicin (86\% each), and ceftriaxone (71\%). Resistance of Group A (19\%) isolates to the used drugs was generally high with exception of amikacin (45\%), cefixime, aztreonam and gentamicin (55\% each). Group B1 (19\%) isolates were highly resistant to all drugs except nalidixic acid (36\%), ciprofloxacin (36\%) and ceftriaxone
(36\%). Phylogenetic group D isolates were found to be most drug resistant followed by phylogenetic group B2, A and B1 (Table 1).

\section{DISCUSSION}

Phylogenetic analysis differentiates all uropathogenic isolates into four groups, A, B1, B2 and D. In our study, $50 \%$ of isolates belonged to group B2, 19\% each represented group $\mathrm{A}$ and $\mathrm{B} 1$ and $12 \%$ were members of group D. Our findings are in line with other studies where it was found that virulent isolates of E. coli mainly belong to phylogenetic group B2 and $\mathrm{D}$, where as less virulent and commensal isolates of $E$. coli belong to phylogenetic groups B1 and A (11). However, we 
found that unlike some previous reports $(2,15)$, phylogenetic group D isolates were less frequent but more drug resistant as compared to phylogenetic groups B2, A and B1 (Table 1). It is difficult to explain but probably different environmental and social conditions play an important role.

All the 59 isolates studied showed resistance to at least 4 drugs by disc diffusion methods. So they can be labeled as MDR $(3,25)$. The emergence of 43 drug resistance patterns showed high variability among local UPEC isolates.

All isolates were highly resistant to ampicillin, which is in agreement to the findings of Nagoba et al. (16). Among cephalosporins, cephradine was totally ineffective, where as aztreonam, ceftriaxone, cefoperazone and cefixime gave much better results with disc diffusion method. There was no significant variation according to phylogenetic groups.

Trimethoprim-sulfamethoxazole has been widely used for the treatment of UTIs $(15,24)$, but our results showed high resistance $(85 \%)$ indicating that it has become ineffective for treatment of UTIs. Similarly, $90 \%$ isolates were resistant to tetracycline. Maynard et al. (13) also reported an increase in the tetracycline resistance in human isolates and considered it as unexpected due to the fact that in humans, tetracycline use is less than in animals.

In the local UPEC isolates, 75\% resistance for nalidixic acid and $69 \%$ for ciprofloxacin were observed. This high occurrence of resistance is in sharp contrast to some older studies. For example Moreno et al. (15) found 21\% resistance to quinolones and $18 \%$ resistance to fluoroquinolone, where as Matthew et al. (12) reported only one ciprofloxacin resistant isolate of E. coli. However, recently Shigemura et al. (22) has reported an emergence of fluoroquinolne resistant $E$. coli responsible for UTIs.

Our study showed that all group D isolates were resistant to quinolones. High level of resistance was also seen in B2 and A groups, where as B1 isolates were mostly susceptible. These findings are in partial disagreement with Takahashi et al. (23) who reported that phylogenetic group B2 was significantly less prevalent in fluoroquinolone resistant $E$. coli than in susceptible $E$. coli (49\% versus $78 \%$ ).

One interesting finding was that the group A isolates which are supposed to represent commensal E. coli exhibited high level of drug resistance which was though less than group $\mathrm{D}$ isolates but was at par with group B2 isolates (11).

Among aminoglycosides, 97\% resistance was observed for streptomycin, $63 \%$ for gentamicin and 56\% for amikacin. As was the case for other drugs, group D was dominant in level of drug resistance. Similar studies indicating relative efficacy of gentamicin and amikacin have been reported from Pakistan (4). However it has also been reported that there is an increase in resistance against these drugs in urinary E. coli (9). These researchers did not study phylogenicity.

It can be concluded that all local UPEC are multiple drug resistant (MDR) which make them a serious and challenging health problem. Prevalence of various phylogenetic groups was in agreement with reported data but strong variance was seen in level of drug resistance. Previous reports indicate that phylogenetic group B2 is more drug resistant where as we found that among local isolates, group D isolates are most problematic in this respect.

\section{ACKNOWLEDGEMENTS}

This work was carried out by the facilities and funding provided by National Institute for Biotechnology and Genetic Engineering (NIBGE), Faisalabad, Pakistan.

\section{REFERENCES}

1. Carvalho, R.H.; Gontijo, F.P.P. (2008). Epidemiologically relevant antimicrobial resistance phenotypes in pathogens isolated from critically ill patients in a Brazilian Universitary Hospital. Braz. J. Microbiol. 39(4): 623-630.

2. Clermont, O.; Bonacorsi, S.; Bingen, E. (2000). Rapid and simple determination of the Escherichia coli phylogenetic groups. Appl. Environ. Microbiol. 66, 4555-4558.

3. Costa, M.M.; Drescher, G.; Maboni, F.; Weber, S.; Botton, S.A.; 
Vainstein, M.H. (2008). Virulence factors and antimicrobial resistance of Escherichia coli isolated from urinary tract of swine in southern of Brazil. Braz. J. Microbiol. 39(4): 741-743.

4. Farooqi, B.J.; Shareeq, F.; Rizvi, Q. K.; Qureshi, H.S.; Ashfaq, M.K. (2000). Changing pattern of antimicrobial susceptibility of organisms causing community acquired urinary tract infections. J. Pak. Med. Assoc. 50, 369-373.

5. Foxman, B. (2003). Epidemiology of urinary tract infections: incidence, morbidity, and economic costs. Dis. Mon. 49, 53-70.

6. Gordon, D.M.; Clermont, O.; Tolley, H.; Denamur, E. (2008). Assigning Escherichia coli strains to phylogenetic groups: multi-locus sequence typing versus the PCR triplex method. Environ. Microbiol. 10, 24842496.

7. Heninger, A.; Binder, M.; Schmidt, S.; Unertl, K.; Botzenhart, K.; Do"Ring, G. (1999). PCR and blood culture of Escherichia coli bacteremia in rats. Ant. Microb. Ag. Chem. 37, 2479-2482.

8. Herzer, P.J.; Inouye, S.; Inouye, M.; Whittam, T.S. (1990). Phylogenetic distribution of branched RNA-linked multicopy single-stranded DNA among natural isolates of Escherichia coli. J. Bacteriol. 172, 6175-6181.

9. Jabeen, K.; Zafar, A.; Hasan, R. (2005). Frequency and sensitivity pattern of extended spectrum $\beta$-Lactamase producing isolates in a tertiary care hospital laboratory of Pakistan. J. Pak. Med. Assoc. 55, 436-439.

10. Johnson, J.R.; Russo, T.A. (2002). Extraintestinal pathogenic Escherichia coli: 'the other bad E coli'. J. Lab. Clin. Med. 3, 155-162.

11. Johnson, J.R.; Stell, A.L. (2000). Extended virulence genotypes of Escherichia coli strains from patients with urosepsis in relation to phylogeny and host compromise. J. Infect. Dis. 181,261-272.

12. Matthew, T.R.; Vega, E.; Pillai, S.D. (2003). Antimicrobial resistance markers of class 1 and class 2 integrons bearing Escherichia coli from irrigation water and sediments. Emerg. Infect. Dis. 9,822-826.

13. Maynard, C.; Bekal, S.; Sanschagrin, F.; Levesque, R.C.; Brousseau, R.; Masson, L. (2004). Heterogeneity among virulence and antimicrobial resistance gene profiles of extraintestinal Escherichia coli isolates of animal and human origin. J. Clin. Microbiol. 42,5444-5452.

14. Miles, T.D.; McLaughlin, W.; Brown, P.D. (2006). Antimicrobial resistance of Escherichia coli isolates from broiler chickens and humans. BMC Vet. Res. 2, 7.

15. Moreno, E.; Prats, G.; Sabaté, M.; Pérez, T.; Johnson, J.R.; Andreu, A.
(2006). Quinolone, fluoroquinolone and trimethoprim sulfamethoxazole resistance in relation to virulence determinants and phylogenetic background among uropathogenic Escherichia coli. J. Antimicrob. Chemother. 57,204-211.

16. Nagoba, B.S.; Wadher, B.J.; Rao, A.K.; Kore, G.D.; Gomashe, A.V.; Ingle, A.B. (2008). A simple and effective approach for the treatment of chronic wound infections caused by multiple antibiotic resistant Escherichia coli. J. Hosp. Infect. 69, 177-180.

17. National Committe for Clinical Laboratory Standards (2004) Performance standards for antimicrobial susceptibility testing. Fourth informational supplement. Document M100-S14. Wayne, PA: NCCLS.

18. Parker, A.S.; Cerhan, J.R.; Lynch, C.F.; Leibovich, B.C.; Cantor, K.P. (2004). History of urinary tract infection and risk of renal cell carcinoma. Am. J. Epidemiol. 159, 42-48.

19. Picard, B.; Goullet, P. (1988). Correlation between electrophoretic types B1 and B2 of carboxylesterase B and host dependent factors in Escherichia coli septicemia. Epidemiol. Infect. 100, 51-61.

20. Sambrook, J.; Fritsch, E.F.; Maniatis, T. (1989). Molecular Cloning: a laboratory manual, $2^{\text {nd }}$ ed, Cold Spring Harbor Laboratory Press, USA.

21. Selander, R.K.; Caugant, D.A.; Whittam, T.S. (1987). Genetic structure and variation in natural populations of Escherichia coli. In: Escherichia coli and Salmonella typhimurium: cellular and molecular biology. ASM Press, Washington, D.C. 1625-1648.

22. Shigemura, K.; Arakawa, S.; Miura, T.; Nakano, Y.; Tanaka, K.; Fujisawa, M. (2008). Significance of fluoroquinolone resistant Escherichia coli in urinary tract infections. Jpn. J. Infect. Dis. 61:226228 .

23. Takahashi, A.; Muratani, T.; Yasuda, M.; Takahashi, S.; Monden, K.; Ishikawa, K. (2009). Genetic profiles of fluoroquinolone-resistant Escherichia coli isolates obtained from patients with cystitis: phylogeny, virulence factors, PAI usp subtypes, and mutation patterns. J. Clin. Microbiol. 47:791-795.

24. Walter, E.; Stamm, M.D. (2001). An epidemic of urinary tract infections. N. Eng. J. Med. 345, 1055-1057.

25. Zhao, S.; Maurer, J.J.; Hubert, S.; De Villena, J.F.; McDermott, P.F.; Meng, J. (2005). Antimicrobial susceptibility and molecular characterization of avian pathogenic Escherichia coli isolates. Vet. Microbiol. 107, 215-224. 